\title{
Appearance and Disappearance of Quasi-Liquid Layers on Ice Crystals in the Presence of Nitric Acid Gas
}

\author{
Ken Nagashima ${ }^{1, *} \mathbb{C}^{\circ}$, Josée Maurais ${ }^{2}{ }^{\oplus}$, Ken-ichiro Murata ${ }^{1}$, Yoshinori Furukawa ${ }^{1} \oplus$, \\ Patrick Ayotte $^{2}\left(\mathbb{D}\right.$ and Gen Sazaki ${ }^{1}$ (i) \\ 1 Institute of Low Temperature Science, Hokkaido University, N19-W8, Kita-ku, Sapporo 060-0819, Japan; \\ murata@lowtem.hokudai.ac.jp (K.-i.M.); frkw@lowtem.hokudai.ac.jp (Y.F.); \\ sazaki@lowtem.hokudai.ac.jp (G.S.) \\ 2 Département de Chimie, Université de Sherbrooke, 2500 Boulevard Université, Sherbrooke, QC J1K 2R1, \\ Canada; Josee.Maurais@usherbrooke.ca (J.M.); Patrick.Ayotte@usherbrooke.ca (P.A.) \\ * Correspondence: nagasima@lowtem.hokudai.ac.jp
}

Received: 23 December 2019; Accepted: 27 January 2020; Published: 29 January 2020

\begin{abstract}
The surfaces of ice crystals near the melting point are covered with thin liquid water layers, called quasi-liquid layers (QLLs), which play crucial roles in various chemical reactions in nature. So far, there have been many spectroscopic studies of such chemical reactions on ice surfaces, however, revealing the effects of atmospheric gases on ice surfaces remains an experimental challenge. In this study, we chose $\mathrm{HNO}_{3}$ as a model atmospheric gas, and directly observed the ice basal faces by advanced optical microscopy under partial pressure of $\mathrm{HNO}_{3}\left(\sim 10^{-4} \mathrm{~Pa}\right)$, relevant to those found in the atmosphere. We found that droplets $\left(\mathrm{HNO}_{3}-\mathrm{QLLs}\right)$ appeared on ice surfaces at temperatures ranging from -0.9 to $-0.2^{\circ} \mathrm{C}$ with an increase in temperature, and that they disappeared at temperatures ranging from -0.6 to $-1.3^{\circ} \mathrm{C}$ with decreasing temperature. We also found that the size of the $\mathrm{HNO}_{3}$-QLLs decreased immediately after we started reducing the temperature. From the changes in size and the liquid-solid phase diagram of the $\mathrm{HNO}_{3}-\mathrm{H}_{2} \mathrm{O}$ binary system, we concluded that the $\mathrm{HNO}_{3}-\mathrm{QLLs}$ did not consist of pure water, but rather aqueous $\mathrm{HNO}_{3}$ solutions, and that the temperature and $\mathrm{HNO}_{3}$ concentration of the $\mathrm{HNO}_{3}-\mathrm{QLLs}$ also coincided with those along a liquidus line.
\end{abstract}

Keywords: ice crystals; quasi-liquid layer; nitric acid gas; optical microscopy

\section{Introduction}

Ice is one of the most abundant materials on Earth, hence, it has a profound and diverse influence on the global environment [1]. In particular, ice crystal surfaces act as "reaction fields" for heterogeneous chemical reactions that involve atmospheric acidic gases [2-4], thereby causing serious environmental issues such as the catalytic ozone depletion by hydrogen chloride gas [5] and the generation of nitrogen oxide gases $\left(\mathrm{NO}_{\mathrm{x}}\right)$ from the photolysis of nitric acid/nitrates [6]. These chemical reactions cannot be explained solely by homogeneous processes. Therefore, there have been many studies of such heterogeneous chemical reactions on ice surfaces, and of the uptake of acidic gases by ice, investigations that have resorted mainly to mass spectroscopy techniques [7]. However, the reported amounts of the uptake showed considerable variations, demonstrating that the mechanisms and rates of acidic gas uptake by ice are still unclear [7].

One of the plausible causes for the considerable variations of the uptake amounts is the presence/absence of thin liquid water layers, so called quasi-liquid layers (QLLs), on ice crystal surfaces at temperatures below the melting point [8-11]. In the case of nitric acid $\left(\mathrm{HNO}_{3}\right)$ gas, heterogeneous 
chemical reactions have so far been studied on ice crystal surfaces in the presence/absence of QLLs. Many researchers have suggested that chemical reactions yielding to the formation of poisonous $\mathrm{NO}_{\mathrm{x}}$ gases occur in QLLs on snow as a result of nitrate photolysis [2,12]. In addition, Marcotte et al. pointed out that such chemical reactions can also occur at temperatures far below the melting point of ice (i.e., as low as $70 \mathrm{~K}$ ), and demonstrated by infrared spectroscopy that heterogeneous photolysis of nitrates adsorbed on amorphous ice surfaces without QLLs can proceed much more effectively than those dissolved with the bulk [13]. To understand the roles of QLLs and of bare ice surfaces in promoting heterogeneous reactions, ice crystal surfaces need to be observed directly in the presence of acidic gases.

As a means in which to conduct direct observation, we, in collaboration with Olympus Engineering Co. Ltd., developed laser confocal microscopy combined with differential interference contrast microscopy (LCM-DIM), which gives interference contrast to objects with a sub-nanometer height on flat surfaces $[14,15]$. Hence, LCM-DIM enables the direct visualization of the $0.37-\mathrm{nm}$-thick elementary steps [16-19] and QLLs on ice crystal surfaces [20-22]. We also found that at temperatures higher than $-2{ }^{\circ} \mathrm{C}$, droplet-type and thin-layer-type QLLs, which are 20 and 200 times less fluidic than bulk water [23], respectively, emerged, in addition to QLLs, so called disordered layers, which appeared at temperatures higher than $-90{ }^{\circ} \mathrm{C}$ [24]. In this study, we observed the basal faces of ice single crystals in the presence of $\mathrm{HNO}_{3}$ gas by LCM-DIM, and investigated the appearance/disappearance temperatures of droplet-type QLLs. We also studied the size changes of QLLs in response to temperature changes, and evaluated the chemical composition and nature of QLLs on ice crystal surfaces.

\section{Materials and Methods}

The observation chamber used for this work was similar to that used in our previous experiments [16]. A cross-sectional schematic illustration of the chamber is shown in Figure 1. The chamber had upper and lower $\mathrm{Cu}$ plates, whose temperatures ( $T$ and $T_{\text {source, }}$, respectively) were separately controlled using independent Peltier elements. On the upper $\mathrm{Cu}$ plate, a cleaved AgI crystal was attached as a substrate for the heterogeneous nucleation of sample ice crystals for the LCM-DIM observation.

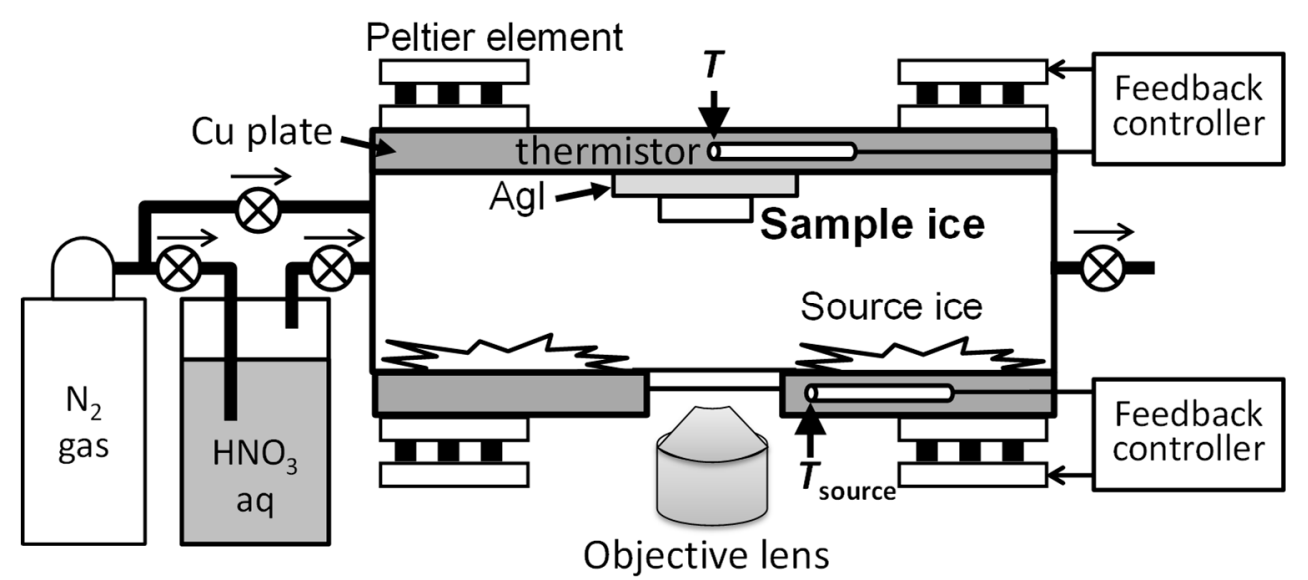

Figure 1. A sectional schematic drawing of the observation chamber. Sample ice crystals prepared for the experiments were grown on a cleaved AgI crystal placed on the upper Cu plate. Source ice crystals were grown on the lower $\mathrm{Cu}$ plate and were used to supply water vapor to the sample ice crystals. Details of the observation chamber can be found in Sazaki et al. (2010) [16]. $\mathrm{HNO}_{3}$ gas was prepared by bubbling nitrogen gas through aqueous $\mathrm{HNO}_{3}$ solutions, and the gas mixture was continuously injected into the chamber at $10 \mathrm{~mL} / \mathrm{min}$.

After $100 \mu \mathrm{L}$ ultrapure water $(>18.2 \mathrm{M} \Omega$ ) was placed on the lower $\mathrm{Cu}$ plate, the observation chamber was filled with nitrogen gas (without $\mathrm{HNO}_{3}$ gas), and then the $T_{\text {source }}$ was lowered to -13 ${ }^{\circ} \mathrm{C}$ to prepare ice crystals (source ice crystals) on the lower $\mathrm{Cu}$ plate. Since the volume of the source 
ice crystals was significantly larger than that of the sample ice crystals, the water vapor pressure $\left(P_{\mathrm{H} 2 \mathrm{O}}\right)$ in the chamber was dominated by the equilibrium water vapor pressure $\left(P_{\mathrm{e}(\mathrm{H} 2 \mathrm{O})}\right)$ of the source ice crystals at $T_{\text {source. }}$. Basal faces of the sample ice Ih crystals used for the experiments were grown heteroepitaxially on the $\mathrm{AgI}$ crystal at $T=-15^{\circ} \mathrm{C}$ under supersaturated water vapor pressure conditions $\left(P_{\mathrm{H} 2 \mathrm{O}}=200 \mathrm{~Pa}\right.$ and $\left.P_{\mathrm{e}(\mathrm{H} 2 \mathrm{O})}=170 \mathrm{~Pa}\right)$.

$\mathrm{HNO}_{3}$ vapors were prepared by bubbling nitrogen gases through aqueous $\mathrm{HNO}_{3}$ solutions of 0.1 and $6.8 \mathrm{~mol} / \mathrm{L}$ at $25^{\circ} \mathrm{C}$. According to the phase diagram, when the bubbled nitrogen gases reached equilibrium with the aqueous $\mathrm{HNO}_{3}$ solutions of 0.1 and $6.8 \mathrm{~mol} / \mathrm{L}$, the partial pressure of $\mathrm{HNO}_{3}$ $\left(P_{\mathrm{HNO} 3}\right)$ in the bubbled nitrogen gases should be $6 \times 10^{-4}$ and $5 \mathrm{~Pa}$, respectively [25]. Here, note that the values of $P_{\mathrm{HNO} 3}$ in the bubbled nitrogen gases were expected not to exceed the theoretical maximum values. Although $P_{\mathrm{HNO} 3}$ in the troposphere shows considerable variations (e.g., ranging from $\sim 10^{-6} \mathrm{~Pa}$ in clean air to $\sim 10^{-2} \mathrm{~Pa}$ in polluted urban air [26,27]), the observations reported in this study were performed under pure nitrogen gas as well as low- and high- $P_{\mathrm{HNO} 3}$ conditions, therefore covered the full range of $P_{\mathrm{HNO} 3}$ reported in the troposphere. The experimental estimate of the actual $P_{\mathrm{HNO} 3}$ supplied to the chamber will be discussed later in the manuscript.

After the sample ice crystals were grown until their lateral size and height reached several hundred $\mu \mathrm{m}$, the bubbled nitrogen gas containing the $\mathrm{HNO}_{3}$ vapor was continuously injected into the observation chamber at $10 \mathrm{~mL} / \mathrm{min}$ throughout the experiment. The bubbled nitrogen gas also included water vapor formed by the bubbling through the aqueous $\mathrm{HNO}_{3}$ solution of 0.1 and 6.8 mol/L: the maximum $P_{\mathrm{H} 2 \mathrm{O}}$ were estimated at 3000 and $400 \mathrm{~Pa}$, respectively [25]. Although the former value was much higher than the $P_{\mathrm{e}(\mathrm{H} 2 \mathrm{O})}$ at $0{ }^{\circ} \mathrm{C}(600 \mathrm{~Pa})$, such water vapor did not affect $P_{\mathrm{H} 2 \mathrm{O}}$ in the observation chamber (i.e., $P_{\mathrm{H} 2 \mathrm{O}}$ was determined only by the water vapor supplied from the source ice crystals). To confirm this scenario, nitrogen gas bubbled through pure water was injected into the chamber at $10 \mathrm{~mL} / \mathrm{min}$, and no effect on the lateral growth speed of elementary steps (growing ends of ubiquitous molecular layers) on the ice basal faces was observed within the accuracy of our experiment. The water vapor formed by the bubbling was injected with enough of a low flow rate, hence such water vapor was condensed on the source ice near the inlet of the gas. In addition, the effects of the temperature $\left(25^{\circ} \mathrm{C}\right)$ during the bubbling could not be observed due to the sufficiently low flow rate and efficient temperature control by Peltier elements. Under the continuous supply of the $\mathrm{HNO}_{3} / \mathrm{N}_{2}$ gas at $10 \mathrm{~mL} / \mathrm{min}$, the basal faces of the sample ice crystals were observed by LCM-DIM at various $T$ (from -10 to $0{ }^{\circ} \mathrm{C}$ ). In addition, the three-dimensional shapes of QLLs that appeared on the basal faces were measured by two-beam interferometry. All experiments were performed under supersaturated water vapor pressure conditions with respect to both ice and liquid water. Therefore, the ice basal faces were always growing and the condensation of water vapor on the QLLs also occurred (no evaporation of the QLLs occurred) continuously during our observations.

\section{Results and Discussion}

\subsection{Appearance of Quasi-Liquid Layer on Ice in the Absence/Presence of $\mathrm{HNO}_{3}$ Gas}

We first investigated the effects of exposure of the ice surfaces to $\mathrm{HNO}_{3}$ gas on the appearance of QLLs on ice basal faces by LCM-DIM (Figure 2). Irrespective of the presence/absence of $\mathrm{HNO}_{3}$ gas, QLLs appeared with increasing $T$. However, $\mathrm{HNO}_{3}$ gas significantly affected the behavior of QLLs.

In the absence of $\mathrm{HNO}_{3}$ gas, QLLs formed on the ice basal face (hereafter, we refer to them as pure-QLLs) showed the shape of a spherical dome (Figure 2a). In Figure 2, the differential interference contrast was adjusted as if the ice crystal surface was illuminated by a light beam slanted from the upper left to the lower-right direction. Hence, the upper-left and lower-right halves of the pure-QLLs appeared white and black, respectively. In addition, note that the pure-QLLs appeared spatially random on the basal face. With increasing $T$, the pure-QLLs appeared at $T$ from -2.5 to $-1.4{ }^{\circ} \mathrm{C}$ (Table 1), and a typical diameter of the pure-QLLs was $\sim 10 \mu \mathrm{m}$. Video of the appearance process of the 
pure-QLLs is available in Video S1 in the Supplementary Materials. Other detailed information on the appearance of the pure-QLLs is presented in our previous works [20-22].

(a) $\mathrm{No} \mathrm{HNO}_{3}, \mathrm{T:}-3.0 \rightarrow-2.5^{\circ} \mathrm{C}$

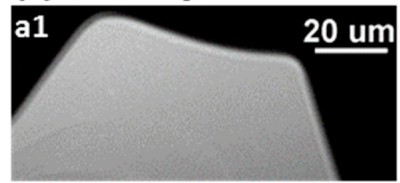

0 sec.

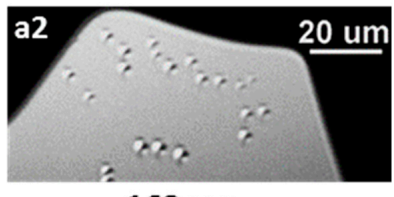

$163 \mathrm{sec}$.

(b) $0.1 \mathrm{~mol} / \mathrm{L} \mathrm{HNO}_{3}$ bubbling, $\mathrm{T:}-0.6 \rightarrow-0.3^{\circ} \mathrm{C}$

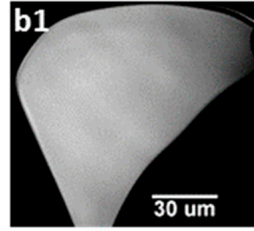

0 sec.

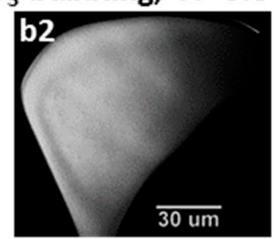

20 sec.

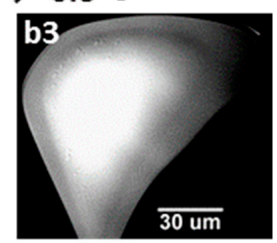

$147 \mathrm{sec}$.

(c) $6.8 \mathrm{~mol} / \mathrm{L} \mathrm{HNO}_{3}$ bubbling, $\mathrm{T:}-2.0 \rightarrow-1.8^{\circ} \mathrm{C}$

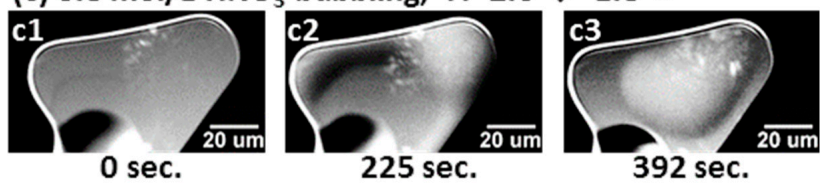

Figure 2. The appearances of QLLs on the ice basal faces in the absence/presence of $\mathrm{HNO}_{3}$ gas with increasing temperature: (a) under pure nitrogen gas, and $(\mathbf{b}, \mathbf{c})$ under nitrogen gases bubbled through aqueous $\mathrm{HNO}_{3}$ solutions of 0.1 (b) and 6.8 (c) mol/L. Videos of the appearance processes (a-c) are available in Videos S1-S3 in the Supplementary Materials, respectively.

Table 1. Partial pressure of $\mathrm{HNO}_{3}$ gas and the appearance and disappearance temperatures of quasi-liquid layers.

\begin{tabular}{lccc}
\hline & \multicolumn{3}{c}{ Experimental Conditions } \\
\cline { 2 - 4 } & Pure & Low $\boldsymbol{P}_{\text {HNO3 }}$ & High $\boldsymbol{P}_{\text {HNO3 }}$ \\
\hline $\mathrm{HNO}_{3}$ concentration in a bubbling solution & - & $0.1 \mathrm{~mol} / \mathrm{L}$ & $6.8 \mathrm{~mol} / \mathrm{L}$ \\
Maximum $P_{\mathrm{HNO}}$ & 0 & $6 \times 10^{-4} \mathrm{~Pa}$ & $5 \mathrm{~Pa}$ \\
Estimated $P_{\mathrm{HNO}}$ & 0 & $\sim 10^{-4} \mathrm{~Pa}$ & $10^{-3}-10^{-2} \mathrm{~Pa}$ \\
Appearance temperature of QLLs & -2.5 to $-1.4{ }^{\circ} \mathrm{C}$ & -0.9 to $-0.2{ }^{\circ} \mathrm{C}$ & -2.5 to $-1.5^{\circ} \mathrm{C}$ \\
(mean \pm standard deviation) & $\left(-1.9 \pm 0.4{ }^{\circ} \mathrm{C}\right)$ & $\left(-0.5 \pm 0.3^{\circ} \mathrm{C}\right)$ & $\left(-1.8 \pm 0.4{ }^{\circ} \mathrm{C}\right)$ \\
Disappearance temperature of QLLs & -2.5 to $-1.8^{\circ} \mathrm{C}$ & -1.3 to $-0.6^{\circ} \mathrm{C}$ & -8.0 to $-6.0^{\circ} \mathrm{C}$ \\
(mean \pm standard deviation) & $\left(-2.2 \pm 0.2^{\circ} \mathrm{C}\right)$ & $\left(-0.9 \pm 0.3^{\circ} \mathrm{C}\right)$ & $\left(-6.4 \pm 0.8^{\circ} \mathrm{C}\right)$ \\
\hline
\end{tabular}

In contrast, in the presence of $\mathrm{HNO}_{3}$ gas, the QLLs appeared preferentially at the periphery of the ice crystal surface (Figure 2b2,c2). However, as shown in Figure 2b,c, these QLLs (hereafter, we refer to them as $\mathrm{HNO}_{3}$-QLLs) did not show a circular drop-like shape as observed in the case of the pure-QLLs (Figure 2a). From the peripheral region of the basal face, the $\mathrm{HNO}_{3}$-QLLs appeared homogeneously (Figure 2b2,c2). This result suggests that the nucleation of the $\mathrm{HNO}_{3}$-QLLs occurred everywhere in the peripheral region, and that the minute $\mathrm{HNO}_{3}$-QLLs may have been formed, they had already coalesced when they reached a size sufficient to be observed by LCM-DIM. The relation between the presence of $\mathrm{HNO}_{3}$ and a nucleation energy barrier for the formation of $\mathrm{HNO}_{3}$-QLLs is an important subject for future studies.

Then, the $\mathrm{HNO}_{3}$-QLLs gradually coalesced to become one big droplet, thereby reducing their surface areas. Since the big resulting $\mathrm{HNO}_{3}$-QLL droplet spontaneously sat at the center of the basal face (Figure 2b3,c3), its shape resembled the outer shape of the ice basal face. The $\mathrm{HNO}_{3}-\mathrm{QLL}$ exhibited a size that was significantly larger than that displayed by the pure-QLLs. Although we could observe such characteristic features during the appearance processes of $\mathrm{HNO}_{3}$-QLLs, irrespective 
of the concentration of $\mathrm{HNO}_{3}$ gas (Figure $2 \mathrm{~b}, \mathrm{c}$ ), the appearance temperatures of the $\mathrm{HNO}_{3}$-QLLs strongly depended on the partial pressure of $\mathrm{HNO}_{3}$ gas. When the nitrogen gases bubbled through aqueous $\mathrm{HNO}_{3}$ solutions of 0.1 and $6.8 \mathrm{~mol} / \mathrm{L}$ were injected into the chamber with increasing $T$, the $\mathrm{HNO}_{3}$-QLLs appeared at $T$ ranging from -0.9 to $-0.2{ }^{\circ} \mathrm{C}$, and from -2.5 to $-1.5{ }^{\circ} \mathrm{C}$, respectively (Table 1). Videos of the appearance processes of the $\mathrm{HNO}_{3}$-QLLs are available in Videos S2 and S3 in the Supplementary Materials.

In the absence of $\mathrm{HNO}_{3}$ gas, we reported that, in addition to the droplet-type QLLs, thin-layer-type QLLs also emerged [20-22]: the thin-layer-type QLLs showed a plain plate shape with a homogeneous thickness of $9 \mathrm{~nm}$ [23]. However, in the presence of $\mathrm{HNO}_{3}$ gas, we did not find the thin-layer-type $\mathrm{HNO}_{3}$-QLLs. Therefore, although at present the reason is unclear, the difference between the behaviors of the emergence of QLLs with the presence and absence of $\mathrm{HNO}_{3}$ gas strongly suggests that the $\mathrm{HNO}_{3}$-QLLs are not composed of pure water, but rather of aqueous $\mathrm{HNO}_{3}$ solutions. This issue will be discussed in Section 3.4.

\subsection{Disappearance of Quasi-Liquid Layers on Ice in the Absence/Presence of $\mathrm{HNO}_{3} \mathrm{Gas}$}

The pure-QLLs and $\mathrm{HNO}_{3}$-QLLs on the ice basal faces disappeared with decreasing $T$ (Figure 3). The disappearance temperature of the pure-QLLs ranged from -1.8 to $-2.5^{\circ} \mathrm{C}$ (Figure 3a and Table 1). By exposing the ice surface to nitrogen gases bubbled through nitric acid solutions of 0.1 and 6.8 $\mathrm{mol} / \mathrm{L}$ and lowering the temperature, the $\mathrm{HNO}_{3}$-QLLs disappeared at $T$ ranging from -0.6 to $-1.3^{\circ} \mathrm{C}$ (Figure $3 b$ ) and from -6.0 to $-8.0^{\circ} \mathrm{C}$ (Figure $3 \mathrm{c}$ ), respectively (Table 1 ). Under high- $P_{\mathrm{HNO}}$ conditions, we found that the disappearance temperature of the $\mathrm{HNO}_{3}$-QLLs was significantly lower, and that the thermal hysteresis between the appearance and disappearance temperatures was larger. However, the disappearance temperature of the pure-QLLs was somewhat lower than that of the $\mathrm{HNO}_{3}$-QLLs under low- $P_{\mathrm{HNO} 3}$ conditions. These results suggest that the disappearance mechanisms of the pure-QLLs and $\mathrm{HNO}_{3}$-QLLs were different. The disappearance mechanisms of the $\mathrm{HNO}_{3}$-QLLs will be discussed in Section 3.5.
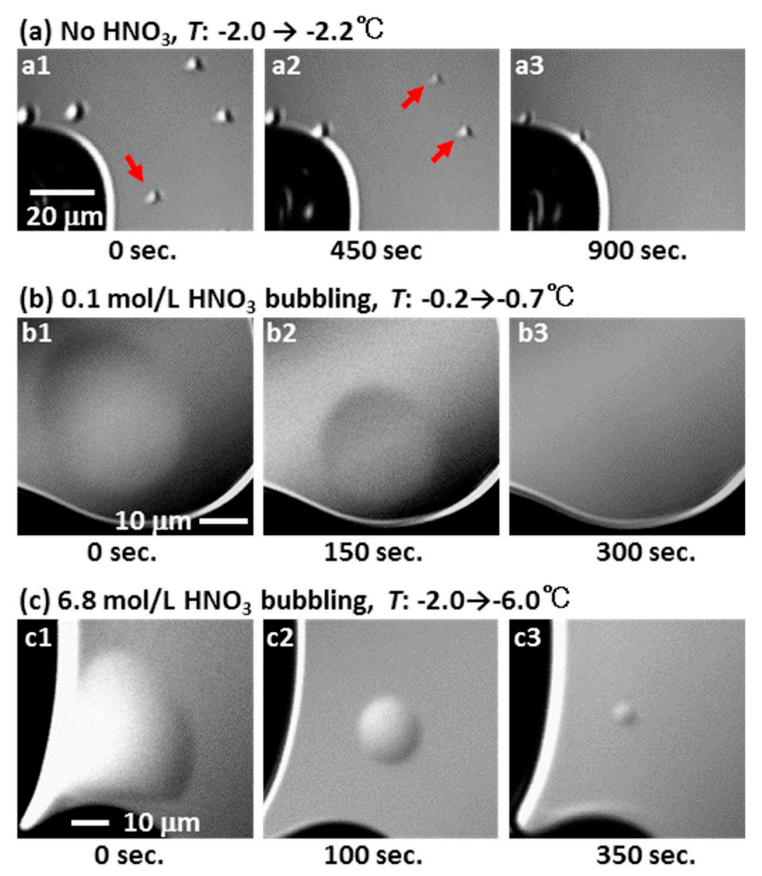

Figure 3. The disappearances of QLLs on ice basal faces in the absence/presence of $\mathrm{HNO}_{3}$ gas with decreasing temperature: (a) under pure nitrogen gas, and $(\mathbf{b}, \mathbf{c})$ under nitrogen gases bubbled through aqueous $\mathrm{HNO}_{3}$ solutions of 0.1 (b) and 6.8 (c) mol/L. QLLs indicated by red arrows in a1 and a2 disappeared in a2 and a3, respectively. 


\subsection{Measurement of Contact Angle for Quasi-Liquid Layer on Ice in the Presence of $\mathrm{HNO}_{3}$ Gas}

To investigate the shape and contact angle of the $\mathrm{HNO}_{3}-\mathrm{QLLs}$ formed on the ice basal faces, we observed them by reflection-type interferometry of the Michelson type [28]. Figure 4a,b show LCM-DIM and interferometric images of the $\mathrm{HNO}_{3}-\mathrm{QLL}$ on the ice basal faces at $T=-0.6{ }^{\circ} \mathrm{C}$, respectively, under the condition of nitrogen gas bubbled through an aqueous $\mathrm{HNO}_{3}$ solution of $0.1 \mathrm{~mol} / \mathrm{L}$. Figure $4 \mathrm{c}$ presents an enlarged image of the area marked by the red dotted rectangle in Figure $4 b$; the image in Figure $4 \mathrm{c}$ is magnified by five times only in the horizontal direction.
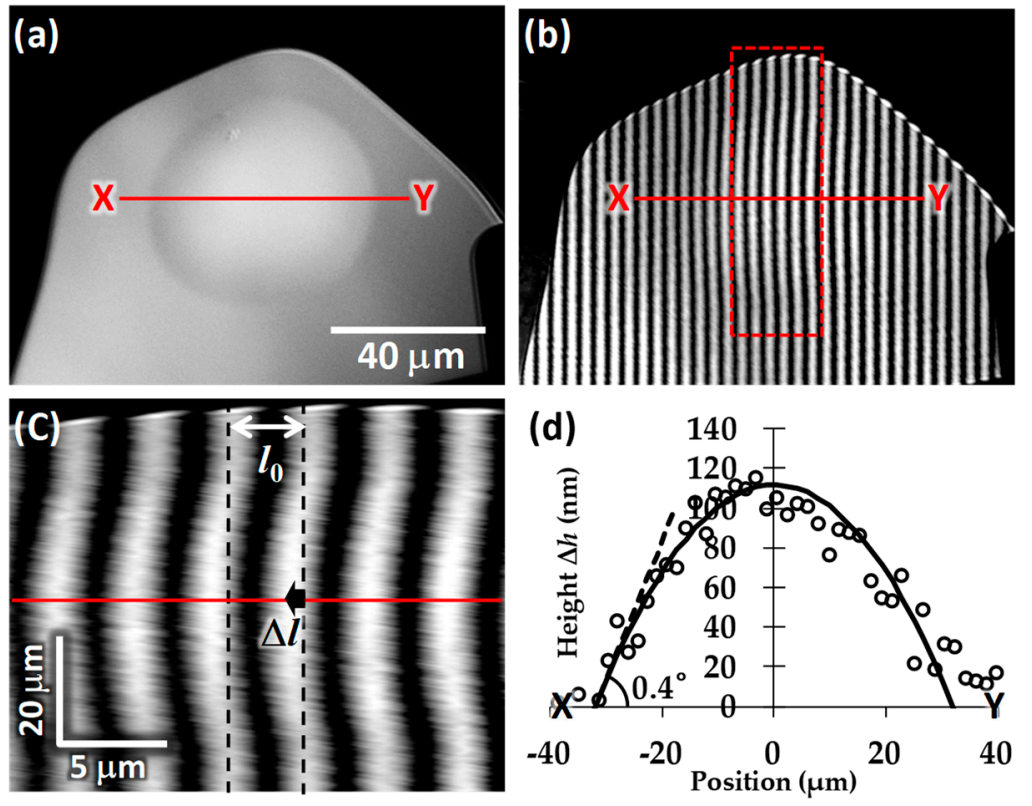

Figure 4. The measurement of the contact angle for $\mathrm{HNO}_{3}-\mathrm{QLL}$ on the ice basal face at $T=-0.6{ }^{\circ} \mathrm{C}$ under nitrogen gas bubbled through an aqueous $\mathrm{HNO}_{3}$ solution of $0.1 \mathrm{~mol} / \mathrm{L}$. (a) An LCM-DIM image, (b) an interferometric image, and (c) an enlarged image of the area marked by the red dotted rectangle in (b) (magnified only in the horizontal direction). (d) The height profile of the $\mathrm{HNO}_{3}$-QLL along the line $\mathrm{X}-\mathrm{Y}$ in (a) and (b). Open circles show the heights of the $\mathrm{HNO}_{3}-\mathrm{QLL}$ calculated by Equation (1). The solid curve shows a fit of the open circles to a spherical dome height profile. The contact angle for $\mathrm{HNO}_{3}$-QLL on the ice basal face was estimated at $0.4^{\circ}$.

On a flat surface, interference fringes show parallel and equally-spaced straight lines. Hence, the bending of the interference fringes in Figure $4 \mathrm{c}$ reveal the three-dimensional outer shape of the $\mathrm{HNO}_{3}$-QLL. The height $\Delta h$ of the $\mathrm{HNO}_{3}$-QLL on the flat basal face can be obtained by

$$
\Delta h=\frac{\lambda}{2 n} \cdot \frac{\Delta l}{l_{0}} .
$$

where $\Delta l$ is the lateral shift of the interference fringe from a straight line (see Figure $4 \mathrm{c}$ ); $\lambda$ is the wavelength of the light source $(680 \mathrm{~nm}) ; n$ is the refractive index of air (1.00); and $l_{0}$ is the distance between the adjacent interference fringes on the flat surface (see Figure 4c).

Open circles in Figure $4 \mathrm{~d}$ present the $\Delta h$ of the $\mathrm{HNO}_{3}$-QLL along the line $\mathrm{X}-\mathrm{Y}$ in Figure $4 \mathrm{a}, \mathrm{b}$. The solid curve shows a fit to a spherical dome height profile. The good agreement between the open circles and the solid curve indicates that the shape of the $\mathrm{HNO}_{3}$-QLL is indeed consistent with that of a spherical dome. From Figure $4 \mathrm{~d}$ and other measurements, under nitrogen gas bubbled through an aqueous $\mathrm{HNO}_{3}$ solution of $0.1 \mathrm{~mol} / \mathrm{L}$, we found that the contact angle for the $\mathrm{HNO}_{3}-\mathrm{QLL}$ on the ice basal face was $0.4^{\circ}$ at $T$ ranging from -0.6 to $-1.0^{\circ} \mathrm{C}$. The value of the contact angle for the $\mathrm{HNO}_{3}$-QLLs was similar to that of pure-QLLs $\left(0.6-2.3^{\circ}\right)$ [22]. 


\subsection{Size Change of Quasi-Liquid Layer in Response to Temperature Change in the Presence of $\mathrm{HNO}_{3}$ Gas}

The size of the $\mathrm{HNO}_{3}$-QLLs started evolving immediately after we suddenly changed $T$. Figure $5 \mathrm{a}$ shows the LCM-DIM images of a $\mathrm{HNO}_{3}$-QLL on an ice basal face exposed to nitrogen gas that was bubbled through an aqueous $\mathrm{HNO}_{3}$ solution of $0.1 \mathrm{~mol} / \mathrm{L}$, just before we reduced the setting of the temperature controller in a stepwise manner (along the temperature program displayed by the solid stepwise line in Figure 5b). We took the images in Figure 5a1-a4 at the moments indicated by arrows a1-a4 in Figure 5b. Black open circles in Figure 5b show the changes in the lateral size (along the line $\mathrm{X}-\mathrm{Y}$ in Figure 5a1) of the $\mathrm{HNO}_{3}-\mathrm{QLL}$ as a function of time. As $\mathrm{T}$ decreased in a stepwise manner, the size of the $\mathrm{HNO}_{3}$-QLL also decreased in a stepwise manner with a delay time of 10-20 s, which corresponded to the delay time of $T$ by the feedback control (Figure 1). In contrast, when we raised $T$ in a similar way, the size of the $\mathrm{HNO}_{3}$-QLL increased reversibly (data not shown). Note that we could not observe such changes in the sizes of pure-QLL with $T$ in the absence of the $\mathrm{HNO}_{3}$ gas. These results clearly demonstrate that the $\mathrm{HNO}_{3}$-QLLs were not pure water, but most probably aqueous $\mathrm{HNO}_{3}$ solutions.

(a)
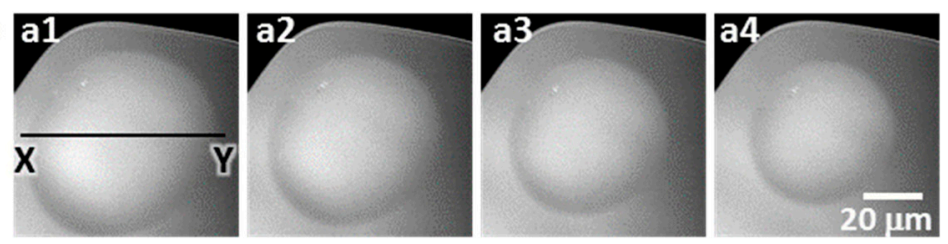

(b)

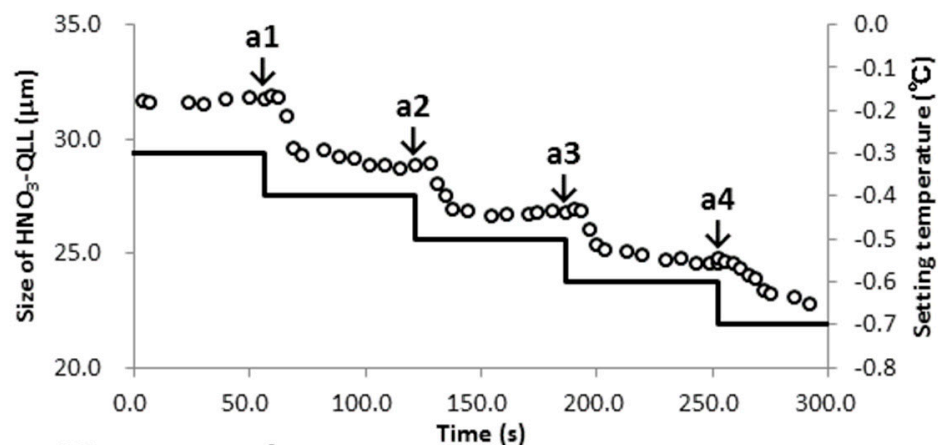

(c)

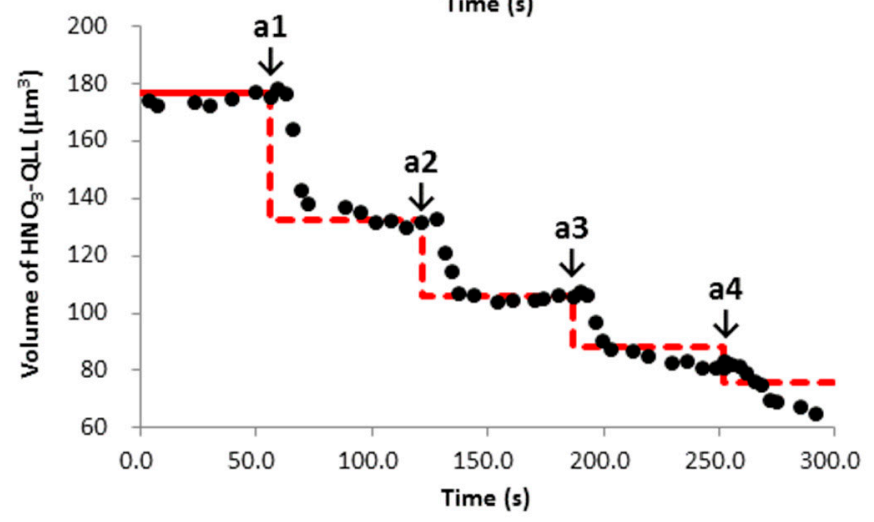

Figure 5. The decrease in the size of a $\mathrm{HNO}_{3}-\mathrm{QLL}$ on an ice basal face with decreasing temperature under conditions where nitrogen gas is bubbled through an aqueous $\mathrm{HNO}_{3}$ solution of $0.1 \mathrm{~mol} / \mathrm{L}$. (a1-4) LCM-DIM images at $T=-0.3,-0.4,-0.5$ and $-0.6{ }^{\circ} \mathrm{C}$, respectively. (b) Changes in the temperature setting of the sample ice crystal (solid line) and in the lateral size of the $\mathrm{HNO}_{3}$-QLL along the line $\mathrm{X}-\mathrm{Y}$ in a1 (black open circles) as a function of time. The images in a1-4 were taken at the moments indicated by arrows a1-4. (c) Changes in the volume of the $\mathrm{HNO}_{3}-\mathrm{QLL}$ (black solid circles) determined experimentally from the diameter and contact angle of the $\mathrm{HNO}_{3}-\mathrm{QLL}$ as a function of time. Red dotted line shows the volume change calculated from the volume at $T=-0.3{ }^{\circ} \mathrm{C}$ (red solid line) using Equation (3). 
How can we explain the changes in the size of the $\mathrm{HNO}_{3}$-QLL with $T$ ? The most plausible explanation is that the $\mathrm{HNO}_{3}$-QLL (aqueous $\mathrm{HNO}_{3}$ solution) and the ice crystals were in equilibrium: we will provide a stricter interpretation later. Hereafter, we try to prove the validity of this scenario. Since the temperature range in Figure 5 was higher than the disappearance temperature, we assumed that the mass of $\mathrm{HNO}_{3}$ in the $\mathrm{HNO}_{3}-\mathrm{QLL}\left(W_{\mathrm{HNO}}[\mathrm{g}]\right)$ was constant during the relatively short observation time period of several minutes: this assumption will be also proven later. Figure 6a shows the phase diagram of a $\mathrm{HNO}_{3}-\mathrm{H}_{2} \mathrm{O}$ binary system, and Figure $6 \mathrm{~b}$ presents the schematic diagram of Figure $6 \mathrm{a}$ in the range of higher temperature and lower $\mathrm{HNO}_{3}$ concentration $(\mathrm{C}[\mathrm{mol} / \mathrm{L}])$. Note that crystals of nitric acid trihydrate, $\mathrm{HNO}_{3} \bullet 3 \mathrm{H}_{2} \mathrm{O}$, are not stable in the temperature range adopted in this study $\left(\mathrm{T}>-10^{\circ} \mathrm{C}\right.$ ) (Figure 6a). As shown in Figure $6 \mathrm{~b}$, when the $\mathrm{HNO}_{3}-\mathrm{QLL}$ and the ice crystals were in equilibrium at $T_{1}$ and $C_{1}$ (at point $X$ in Figure $6 \mathrm{~b}$ ), we reduced the $T$ suddenly from $T_{1}$ to $T_{2}$, which meant that the systems fell out of equilibrium. Just after the rapid decrease in $T$ (say down to point $Y$ in Figure $6 \mathrm{~b}$ ), the $\mathrm{HNO}_{3}$-QLL became supercooled. Then, water froze out of the $\mathrm{HNO}_{3}$-QLL (thereby fueling the growth of the underlying ice crystal), resulting in an increase in $C$. The freezing of water out of the $\mathrm{HNO}_{3}$-QLL stopped when $C$ reached $C_{2}$, since the $\mathrm{HNO}_{3}-\mathrm{QLL}$ and the ice crystal were now back in equilibrium (at point $\mathrm{Z}$ in Figure $6 \mathrm{~b}$ ). In this case, the volume of the $\mathrm{HNO}_{3}$-QLL $V \mu \mathrm{m}^{3}$ at $T_{1}$ and $T_{2}\left(V_{1}\right.$ and $\left.V_{2}\right)$ can be obtained by

$$
V_{1}=\frac{W_{\mathrm{HNO}_{3}}}{M_{\mathrm{HNO}_{3}} \cdot C_{1}} \times 10^{15} \mu \mathrm{m}^{3} / \mathrm{L} \text { and } V_{2}=\frac{W_{\mathrm{HNO}_{3}}}{M_{\mathrm{HNO}_{3}} \cdot C_{2}} \times 10^{15} \mu \mathrm{m}^{3} / \mathrm{L} .
$$

where $M_{\mathrm{HNO}}$ is the molar mass of $\mathrm{HNO}_{3}$ (i.e., $63.0 \mathrm{~g} / \mathrm{mol}$ ). Under conditions where $W_{\mathrm{HNO} 3}$ is constant, $V_{2}$ can be obtained by

$$
V_{2}=\frac{C_{1}}{C_{2}} V_{1}
$$
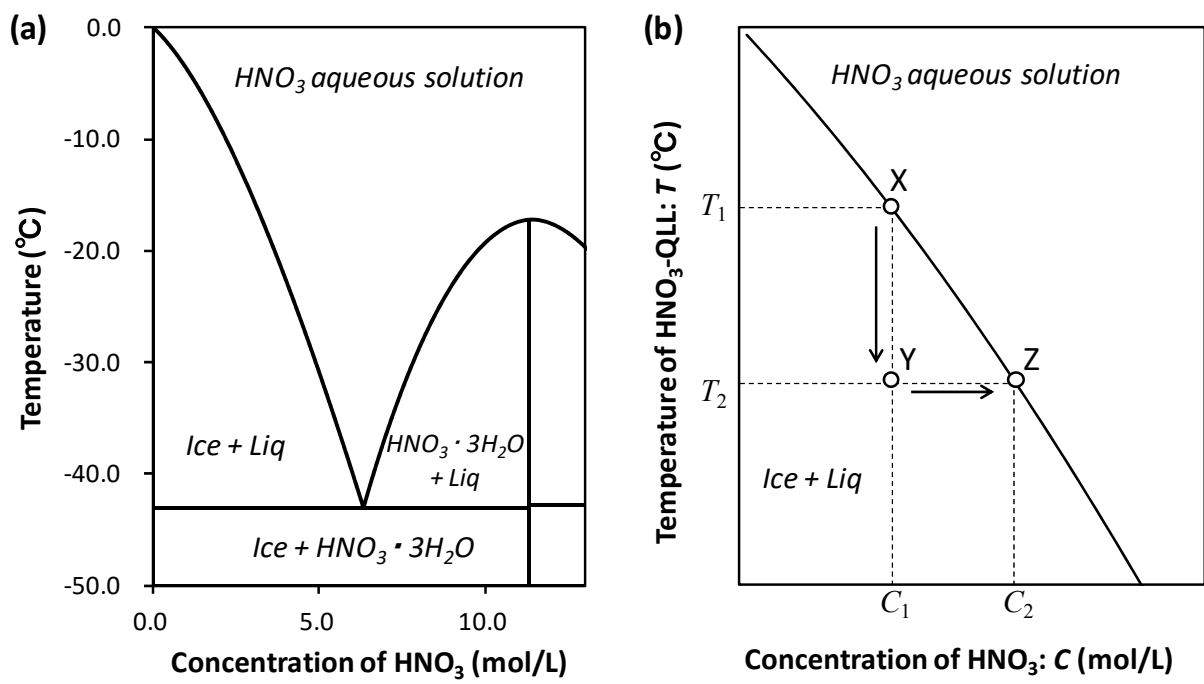

Figure 6. (a) Details of the phase diagram of the $\mathrm{HNO}_{3}-\mathrm{H}_{2} \mathrm{O}$ binary system after Beyer and Hansen [29]. (b) A schematic phase diagram (a liquidus line in the range of higher temperature and lower $\mathrm{HNO}_{3}$ concentrations) that illustrates the increase in $C$ of the $\mathrm{HNO}_{3}$-QLL from $C_{1}$ to $C_{2}$ upon cooling from $T_{1}$ to $T_{2}$, following the observations reported in Figure 5.

Therefore, when we reduce $T$ in a stepwise manner, $V$ also decreases in a stepwise manner according to Equation (3).

We verified the above scenario by calculating the changes in $V$ as a function of $T$. The black solid circles in Figure 5c show $V$ was determined experimentally from the LCM-DIM images in Figure 5 a. We obtained $W_{\mathrm{HNO} 3}=9.26 \times 10^{-13} \mathrm{~g}$ (displayed as a red solid line in Figure $5 \mathrm{c}$ ) using the values of $V$ 
$\left(177.0 \mu \mathrm{m}^{3}\right)$ from Figure $5 \mathrm{c}$ and $C(0.083 \mathrm{~mol} / \mathrm{L})$ from Figure $6 \mathrm{a}$ at $T=-0.3^{\circ} \mathrm{C}$. We then calculated $V$ at $T$ other than $-0.3^{\circ} \mathrm{C}$ by using the value of $W_{\mathrm{HNO}}$ and Equation (3). Figure $5 \mathrm{c}$ shows that the calculated $V$ (shown by the red dotted line) was in good agreement with the $V$ determined experimentally (the black solid circles) in the range of $T=-0.4$ to $-0.6{ }^{\circ} \mathrm{C}$ (50-250 s). This result demonstrates that the $\mathrm{HNO}_{3}$-QLL was indeed not pure water, but rather an aqueous $\mathrm{HNO}_{3}$ solution, and also that the $\mathrm{HNO}_{3}$-QLL and the ice crystal were in equilibrium.

In addition, here we need to give a stricter interpretation. Since we performed all experiments under supersaturated water vapor pressure conditions, condensation of water vapor on the $\mathrm{HNO}_{3}$-QLL also occurred, potentially resulting in the decrease in $C$ (hence causing the $\mathrm{HNO}_{3}$-QLL to become supercooled). However, the water froze out of the $\mathrm{HNO}_{3}$-QLL (thereby causing the underlying ice crystal to grow) much faster than the condensation of water vapor [30], since the growth process of ice in liquid water does not include any mass transfer process. Hence, the value of $C$ could be kept constant at the equilibrium value. Therefore, strictly speaking, we should explain such situations as not "in equilibrium" but as "in a steady state under conditions along the liquidus line".

\subsection{Disappearance Mechanism of Quasi-Liquid Layer on Ice in the Presence of $\mathrm{HNO}_{3}$ Gas}

Figure $5 \mathrm{c}$ also shows that the black solid circles exhibited a larger disagreement with the red dotted line as $T$ further decreased (see $T=-0.7^{\circ} \mathrm{C}$ after $250 \mathrm{~s}$ in Figure $5 \mathrm{c}$ ). This disagreement was probably due to the decrease in $W_{\mathrm{HNO}}$ after $T$ became smaller than the disappearance temperature of the $\mathrm{HNO}_{3}$-QLLs $\left(T=-0.6\right.$ to $\left.-1.3^{\circ} \mathrm{C}\right)$. One of the plausible causes for the decrease in $W_{\mathrm{HNO} 3}$ could be the evaporation of $\mathrm{HNO}_{3}$ from the $\mathrm{HNO}_{3}$-QLLs. We checked this possibility as follows. In our system, with decreasing $T, C$ increased according to the phase diagram (Figure $6 \mathrm{~b}$ ). Then, at a certain $T$, we first obtained the value of $C$ from the phase diagram. Next, we calculated the equilibrium $\mathrm{HNO}_{3}$ partial vapor pressure, $P_{\mathrm{e}(\mathrm{HNO})}$, of the $\mathrm{HNO}_{3}$-QLLs, using the value of $C$ determined from Figure 6 and the vapor-liquid equilibrium curve [25], the results of which are summarized in Figure 7. Indeed, as $T$ decreases, $P_{\mathrm{e}(\mathrm{HNO} 3)}$ increases. It is very reasonable to expect that when $P_{\mathrm{e}(\mathrm{HNO})}$ exceeds $P_{\mathrm{HNO} 3}$ in the observation chamber with decreasing $T, \mathrm{HNO}_{3}$ evaporates from the $\mathrm{HNO}_{3}$-QLLs, resulting in the decrease in $V$ according to Equation (2) and also in the disappearance of the $\mathrm{HNO}_{3}$-QLLs. From $P_{\mathrm{e} \text { (HNO3) }}$ (the solid curve in Figure 7) and the disappearance temperatures of the $\mathrm{HNO}_{3}$-QLLs under the nitrogen gases bubbled through $\mathrm{HNO}_{3}$ solutions of 0.1 and $6.8 \mathrm{~mol} / \mathrm{L}$ (Table 1), $P_{\mathrm{HNO}}$ in the chamber was estimated to be $\sim 10^{-4}$ and $10^{-3}-10^{-2} \mathrm{~Pa}$ (red and blue dashed lines in Figure 7 and Table 1), respectively. The estimated $P_{\mathrm{HNO} 3}$ values in the observation chamber were thus indeed smaller than the maximum $P_{\mathrm{HNO} 3}$ estimated from the equilibrium vapor pressure over aqueous $\mathrm{HNO}_{3}$ solutions of 0.1 and $6.8 \mathrm{~mol} / \mathrm{L}$, that is $6 \times 10^{-4}$ and $5 \mathrm{~Pa}$, respectively. Hence, we expect that this scenario is plausible, although we have no direct evidence.

It is also important to evaluate how significant the uptake of $\mathrm{HNO}_{3}$ by the bulk of the ice crystal is under the conditions of our observations. However, since the solubility of nitrate ions in ice is estimated to be $\sim 10^{-5} \mathrm{~mol} \%$ in our experimental temperature range (from -10 to $0{ }^{\circ} \mathrm{C}$ ) [31], we can safely neglect the contribution from the uptake of $\mathrm{HNO}_{3}$ by bulk ice in this study.

When we reduced $T$ to a temperature much lower than the disappearance temperature, we observed the formation of macrosteps (steps with a height much larger than that of elementary steps). This observation supports the interpretation that partial freezing of the $\mathrm{HNO}_{3}$-QLLs can follow a decrease in $T$, eventually causing the complete disappearance of the $\mathrm{HNO}_{3}-\mathrm{QLLs}$. Figure 8a shows a series of LCM-DIM images of an $\mathrm{HNO}_{3}$-QLL on an ice basal face when we reduced $T$ from -0.5 to $-4.7^{\circ} \mathrm{C}$ under nitrogen gas bubbled through an aqueous $\mathrm{HNO}_{3}$ solution of $0.1 \mathrm{~mol} / \mathrm{L}$. A macrostep appeared along the periphery of the $\mathrm{HNO}_{3}$-QLL and kept growing laterally for a few tens of seconds (marked by red arrows in Figure 8a2-a4). At the same time, the size of the $\mathrm{HNO}_{3}$-QLL became rapidly smaller. Figure $8 \mathrm{~b}$ shows a schematic illustration of the phenomena observed in Figure 8a. First, the $\mathrm{HNO}_{3}$-QLL is in equilibrium with the ice crystal (Figure $8 \mathrm{~b} 1$ ). When we reduce $T$ by a large amount (from $\mathrm{X}$ to $\mathrm{Y}$ in Figure 6b), part of the water in the $\mathrm{HNO}_{3}$-QLL must freeze to reestablish equilibrium 
with the ice crystal, resulting in the increase in $C$ (from $Y$ to $Z$ in Figure $6 b$ ). Since the homogeneous nucleation of ice crystals in the $\mathrm{HNO}_{3}$-QLL is kinetically much more difficult than the growth, the growth of the underlying ice preferentially starts from the interface between the $\mathrm{HNO}_{3}$-QLL and the ice crystal. Then, the interface grows evenly in the vertical direction (Figure 8b2): such growth behavior is well known as the vapor-liquid-solid (VLS) growth mechanism [32], which usually causes the growth of whisker crystals. After the vertical growth, the lateral face of the ice step made by the vertical ice growth in the $\mathrm{HNO}_{3}$-QLL (black arrowheads in Figure 8b2) is exposed to supersaturated water vapor. Hence, the ice step further grows in the lateral direction fueled by water vapor (Figure 8b3): we observed the growth front of the ice step as the macrostep (Figure 8a2-4). Therefore, the formation of the macrosteps, induced by the significant decrease in $T$, demonstrates the freezing of water from the $\mathrm{HNO}_{3}$-QLLs (causing the underlying ice to grow evenly in the vertical direction) until equilibrium between the $\mathrm{HNO}_{3}$-QLLs and ice crystals is achieved. Video of the formation process of the macrostep from the $\mathrm{HNO}_{3}$-QLL are available in Video $\mathrm{S} 4$ in the Supplementary Materials.

Temperature of $\mathrm{HNO}_{3}-\mathrm{QLL}: T\left({ }^{\circ} \mathrm{C}\right)$

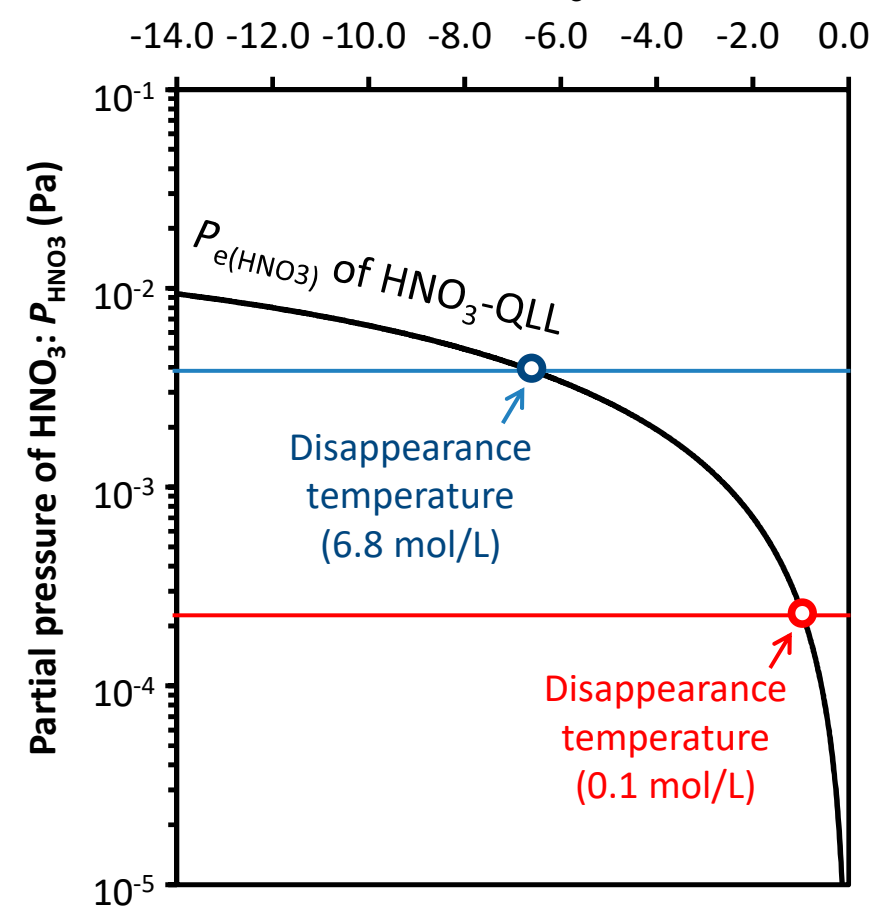

Figure 7. The changes in the equilibrium partial vapor pressure of $\mathrm{HNO}_{3}, P_{\mathrm{e}(\mathrm{HNO})}$, of $\mathrm{HNO}_{3}-\mathrm{QLLs}$ (black solid curve) as a function of temperature. Red and blue lines show the partial pressures of $\mathrm{HNO}_{3}$ gas estimated from the disappearance temperatures (red and blue open circles) of the $\mathrm{HNO}_{3}$-QLLs under nitrogen gases bubbled through aqueous $\mathrm{HNO}_{3}$ solutions of 0.1 and $6.8 \mathrm{~mol} / \mathrm{L}$, respectively.

As explained above, the disappearance mechanism of the $\mathrm{HNO}_{3}$-QLLs can be explained by the equilibrium of the $\mathrm{HNO}_{3}$ component between the $\mathrm{HNO}_{3}$-QLLs and the ambient gas. That is to say, the $\mathrm{HNO}_{3}$-QLLs are not quasi liquid (whose properties are significantly different from those of bulk water), but an aqueous $\mathrm{HNO}_{3}$ solution (which can exist as a thermodynamically stable bulk phase). In contrast, the appearance mechanism of the $\mathrm{HNO}_{3}$-QLLs cannot be explained by the same equilibrium of the $\mathrm{HNO}_{3}$ component since the appearance temperatures of the pure- and $\mathrm{HNO}_{3}$-QLLs were almost same (Table 1), although the appearance/disappearance temperatures of the $\mathrm{HNO}_{3}$-QLLs exhibited a large hysteresis. At present, we suppose that at first, the $\mathrm{HNO}_{3}$-QLLs appeared as a quasi-liquid, but immediately became a thermodynamically stable aqueous solution of $\mathrm{HNO}_{3}$. 

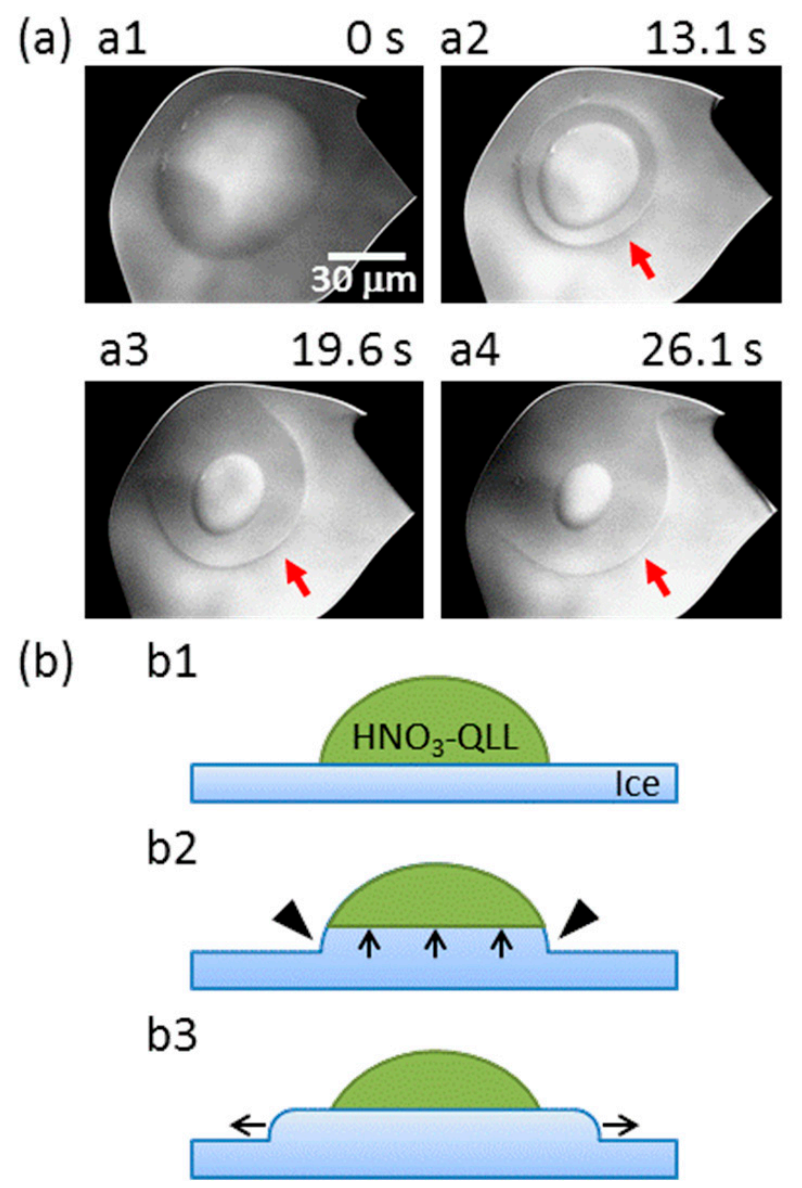

Figure 8. The formation of a macrostep from a $\mathrm{HNO}_{3}-\mathrm{QLL}$ on an ice basal face following a large sudden decrease in temperature. (a) LCM-DIM images of the $\mathrm{HNO}_{3}-\mathrm{QLL}$ when we reduced $T$ from -0.5 to $-4.7^{\circ} \mathrm{C}$ under nitrogen gas bubbled through an aqueous $\mathrm{HNO} 3$ solution of $0.1 \mathrm{~mol} / \mathrm{L}$. Red arrows show the edge of the macrostep. (b) Schematic illustrations of the formation of the macrostep from the $\mathrm{HNO}_{3}$-QLL. $(\mathrm{b} 1, \mathrm{~b} 2)$ When part of the $\mathrm{HNO}_{3}$-QLL freezes, the interface between the $\mathrm{HNO}_{3}$-QLL and the ice crystal grows evenly in the vertical direction, resulting in the formation of a thick ice step (black arrowheads). The lateral face of the ice step is therefore exposed to supersaturated water vapor. (b3) The ice macrostep then grows in the lateral direction utilizing water vapor molecules outside of the $\mathrm{HNO}_{3}$-QLL. Video of the formation process of the macrostep is available in Video S4 in the Supplementary Materials.

\subsection{Comparison between Quasi-Liquid Layer in Our Experiments and Quasi-Liquid Layer in Nature}

In this study, from the disappearance temperature of the $\mathrm{HNO}_{3}-\mathrm{QLL}$, we estimated $P_{\mathrm{HNO}}$ under nitrogen gases bubbled through aqueous $\mathrm{HNO}_{3}$ solutions of 0.1 and $6.8 \mathrm{~mol} / \mathrm{L}$ to be $\sim 10^{-4}$ and $10^{-3}-10^{-2}$ $\mathrm{Pa}$, respectively. Hence, we expect that QLLs on ice under typical atmospheric conditions in the natural environment $\left(P_{\mathrm{HNO}}=\sim 10^{-6} \mathrm{~Pa}[26,27]\right)$ would show a behavior intermediate between those observed under exposure either to pure nitrogen gas or to low- $P_{\mathrm{HNO}}$ conditions: $\mathrm{HNO}_{3}-\mathrm{QLLs}$ could disappear below $\sim-1^{\circ} \mathrm{C}$ (Figure 3 and Table 1$)$. In polluted urban areas $\left(P_{\mathrm{HNO}}=\sim 10^{-2} \mathrm{~Pa}[26,27]\right)$, the disappearance temperature of $\mathrm{HNO}_{3}$-QLLs could be reduced to $\sim-6{ }^{\circ} \mathrm{C}$ (Figure 3 and Table 1).

There also exist other factors that may need to be considered. In this study, we used the basal faces of ice single crystals. However, a large proportion of ice in nature is present as polycrystals, which have grain boundaries, defects, various high-index faces and impurities. Therefore, we will need to study the effects of these features on the behavior of $\mathrm{HNO}_{3}-\mathrm{QLLs}$ in the future.

In addition, various kinds of gases exist in the natural environment. Hence, many studies have been so far performed using various chemical analysis techniques [7]. However, there exist few studies 
that have taken advantage of direct observation. Recently, we studied the effects of hydrogen chloride gas on the behavior of QLLs (hereafter referred to as HCl-QLLs) on ice basal faces [33,34]. In this case, we found that the HCl-QLLs were aqueous hydrochloric acid solution, and that the temperature and $\mathrm{HCl}$ concentration of the $\mathrm{HCl}$-QLLs were also very close to those of a liquidus line: these results were similar to those found in this study. However, we also found phenomena different from those displayed by the $\mathrm{HNO}_{3}$-QLLs. The HCl-QLLs did not disappear with decreasing $\mathrm{T}$ until $-15{ }^{\circ} \mathrm{C}$ (the minimum temperature adopted in the study) [33]. In addition, the growth of ice started preferentially from droplet-ice-vapor contact lines, thereby causing the HCl-QLLs to become embedded within ice crystals without freezing [34]: no VLS growth occurred contrary to the case of the $\mathrm{HNO}_{3}$-QLLs (Figure $8 \mathrm{~b} 2$ ). In the previous studies, we used a $\mathrm{HCl}$ partial pressure of $100 \mathrm{~Pa}$, which was four orders of magnitude greater than the $P_{\mathrm{HNO} 3}$ used in this study: the most stable phase at $-15^{\circ} \mathrm{C}$ was probably not a solid solution of $\mathrm{HCl}$ in ice, but rather aqueous a hydrochloric acid solution [7,33,34]. Hence, at present, it is unclear whether the different behaviors of the $\mathrm{HCl}$ - and $\mathrm{HNO}_{3}$-QLLs were due to differences in the physical/chemical properties of $\mathrm{HCl}$ and $\mathrm{HNO}_{3}$, or rather to the differences in the partial pressures used in the two studies.

\section{Conclusions}

We prepared low- and high- $P_{\mathrm{HNO}}$ conditions by bubbling nitrogen gases through aqueous $\mathrm{HNO}_{3}$ solutions of 0.1 and $6.8 \mathrm{~mol} / \mathrm{L}$, estimated to yield a maximum $P_{\mathrm{HNO} 3}$ of $6 \times 10^{-4}$ and $5 \mathrm{~Pa}$, respectively. Then, we visualized the $\mathrm{HNO}_{3}$-QLLs on the ice basal faces in the presence of $\mathrm{HNO}_{3}$ gas directly by LCM-DIM, and obtained the following key results:

- Irrespective of the presence/absence of the $\mathrm{HNO}_{3}$ gas, the pure-QLLs and $\mathrm{HNO}_{3}$-QLLs appeared with increasing $T$ and disappeared with decreasing $T$. The appearance temperatures of the $\mathrm{HNO}_{3}$-QLLs upon heating under the low- and high- $P_{\mathrm{HNO}}$ conditions were not so different, however, the disappearance temperature of the $\mathrm{HNO}_{3}$-QLLs upon cooling under high- $P_{\mathrm{HNO}}$ conditions was significantly lower than that observed under low- $P_{\mathrm{HNO}}$ conditions.

- From the changes in the volume of the $\mathrm{HNO}_{3}$-QLLs following changes in temperature, and also from the liquid-solid phase diagram of the $\mathrm{HNO}_{3}-\mathrm{H}_{2} \mathrm{O}$ binary system, we found that, in the presence of $\mathrm{HNO}_{3}$ gas, the $\mathrm{HNO}_{3}$-QLLs on the ice basal faces were aqueous $\mathrm{HNO}_{3}$ solutions, whose temperature and $\mathrm{HNO}_{3}$ concentration coincided with those along the liquidus line.

- From the disappearance temperatures of the $\mathrm{HNO}_{3}$-QLLs on the ice basal faces, we estimated $P_{\mathrm{HNO} 3}$ under low- and high- $P_{\mathrm{HNO} 3}$ conditions to be $\sim 10^{-4}$ and $10^{-3}-10^{-2} \mathrm{~Pa}$, respectively. These two values were smaller than the maximum $P_{\mathrm{HNO} 3}$ estimated from the equilibrium aqueous $\mathrm{HNO}_{3}$ solutions vapor pressures of $5 \times 10^{-4}$ and $6 \mathrm{~Pa}$, respectively.

Supplementary Materials: The following are available online at http://www.mdpi.com/2073-4352/10/2/72/s1, Video S1: Appearance process of pure-QLL on the ice basal face with increasing temperature from -3.0 to -2.5 ${ }^{\circ} \mathrm{C}$ in the absence of $\mathrm{HNO}_{3}$ gas (Figure 2a), Video S2: Appearance process of $\mathrm{HNO}_{3}$-QLL on the ice basal face with increasing temperature from -0.6 to $-0.3^{\circ} \mathrm{C}$ under low $-P_{\mathrm{HNO}}$ condition (Figure $2 \mathrm{~b}$ ), Video S3: Appearance process of $\mathrm{HNO}_{3}$-QLL on the ice basal face with increasing temperature from -2.0 to $-1.8^{\circ} \mathrm{C}$ under high- $P_{\mathrm{HNO}}$ condition (Figure $2 \mathrm{c}$ ), Video S4: Formation of macrostep from $\mathrm{HNO}_{3}-\mathrm{QLL}$ on the ice basal face with decreasing temperature from -0.5 to $-4.7^{\circ} \mathrm{C}$ under low- $P_{\mathrm{HNO}}$ condition (Figure $8 \mathrm{a}$ ).

Author Contributions: Conceptualization, K.N., Y.F., P.A. and G.S.; Methodology and validation, K.N., K.M., and G.S.; Formal analysis, data curation, supervision, and project administration, K.N.; Investigation, K.N. and J.M.; Writing—original draft preparation, K.N. and G.S.; Writing—review and editing, K.N., J.M., P.A., and G.S. All authors have read and agreed to the published version of the manuscript.

Funding: This research was funded by JSPS KAKENHIs (grant numbers 17K05604 (K.N.) and 19H02611 (G.S.)), the Short-term JSPS Bridge fellowship (S16129 (P.A.)), and the JSPS Summer Program (SP18413 (J.M.)).

Acknowledgments: The authors thank Y. Saito, S. Kobayashi, K. Ishihara, and G. Ryu (Olympus Corporation) for their technical support of the laser confocal microscopy instrumentation; J. Chen (Hokkaido University) for providing the experimental data; and T. Hama (Hokkaido University) for their valuable discussion.

Conflicts of Interest: The authors declare no conflicts of interest. 


\section{References}

1. Bartels-Rausch, T. Chemistry: Ten things we need to know about ice and snow. Nature 2013, 494, $27-29$. [CrossRef] [PubMed]

2. Grannas, A.M.; Jones, A.E.; Dibb, J.; Ammann, M.; Anastasio, C.; Beine, H.J.; Bergin, M.; Bottenheim, J.; Boxe, C.S.; Carver, G.; et al. An overview of snow photochemistry: Evidence, mechanisms and impacts. Atmos. Chem. Phys. Discuss. 2007, 7, 4165-4283. [CrossRef]

3. Domine, F.; Bock, J.; Voisin, D.; Donaldson, D.J. Can We Model Snow Photochemistry? Problems with the Current Approaches. J. Phys. Chem. A 2013, 117, 4733-4749. [CrossRef] [PubMed]

4. Bartels-Rausch, T.; Jacobi, H.-W.; Kahan, T.F.; Thomas, J.L.; Thomson, E.S.; Abbatt, J.P.D.; Ammann, M.; Blackford, J.R.; Bluhm, H.; Boxe, C.; et al. A review of air-ice chemical and physical interactions (AICI): Liquids, quasi-liquids, and solids in snow. Atmos. Chem. Phys. 2014, 14, 1587-1633. [CrossRef]

5. Solomon, S. Stratospheric ozone depletion: A review of concepts and history. Rev. Geophys. 1999, 37, $275-316$. [CrossRef]

6. Dominé, F.; Shepson, P.B. Air-snow interactions and atmospheric chemistry. Science 2002, 297, $1506-1510$. [CrossRef]

7. Huthwelker, T.; Ammann, M.; Peter, T. The uptake of acidic gases on ice. Chem. Rev. 2006, 106, 1375-1444. [CrossRef]

8. Elbaum, M.; Lipson, S.G.; Dash, J.G. Optical study of surface melting on ice. J. Cryst. Growth 1993, 129, 491-505. [CrossRef]

9. Petrenko, V.F.; Whitworth, R.W. Physics of Ice; Oxford University Press: Oxford, UK, 1999; ISBN 9780198518945.

10. Li, Y.; Somorjai, G.A. Surface Premelting of Ice. J. Phys. Chem. C 2007, 111, 9631-9637. [CrossRef]

11. Gelman Constantin, J.; Gianetti, M.M.; Longinotti, M.P.; Corti, H.R. The quasi-liquid layer of ice revisited: The role of temperature gradients and tip chemistry in AFM studies. Atmos. Chem. Phys. Discuss. 2018, 18, 14965-14978. [CrossRef]

12. Boxe, C.S.; Saiz-Lopez, A. Multiphase modeling of nitrate photochemistry in the quasi-liquid layer (QLL): Implications for NOx release from the Arctic and coastal Antarctic snowpack. Atmos. Chem. Phys. 2008, 8, 4855-4864. [CrossRef]

13. Marcotte, G.; Marchand, P.; Pronovost, S.; Ayotte, P.; Laffon, C.; Parent, P. Surface-Enhanced Nitrate Photolysis on Ice. J. Phys. Chem. A 2015, 119, 1996-2005. [CrossRef] [PubMed]

14. Sazaki, G.; Matsui, T.; Tsukamoto, K.; Usami, N.; Ujihara, T.; Fujiwara, K.; Nakajima, K. In situ observation of elementary growth steps on the surface of protein crystals by laser confocal microscopy. J. Cryst. Growth 2004, 262, 536-542. [CrossRef]

15. Komatsu, H.; Sazaki, G. Differential interference contrast microscopy/phase-contrast microscopy. In Compendium of Surface and Interface Analysis; The Surface Science Society of Japan, Ed.; Springer: Singapore, 2018; pp. 55-60. ISBN 978-981-10-6155-4.

16. Sazaki, G.; Zepeda, S.; Nakatsubo, S.; Yokoyama, E.; Furukawa, Y. Elementary steps at the surface of ice crystals visualized by advanced optical microscopy. Proc. Natl. Acad. Sci. 2010, 107, 19702-19707. [CrossRef] [PubMed]

17. Sazaki, G.; Asakawa, H.; Nagashima, K.; Nakatsubo, S.; Furukawa, Y. Double Spiral Steps on I Ice Crystal Surfaces Grown from Water Vapor Just below the Melting Point. Cryst. Growth Des. 2014, 14, $2133-2137$. [CrossRef]

18. Asakawa, H.; Sazaki, G.; Yokoyama, E.; Nagashima, K.; Nakatsubo, S.; Furukawa, Y. Roles of Surface/Volume Diffusion in the Growth Kinetics of Elementary Spiral Steps on Ice Basal Faces Grown from Water Vapor. Cryst. Growth Des. 2014, 14, 3210-3220. [CrossRef]

19. Inomata, M.; Murata, K.; Asakawa, H.; Nagashima, K.; Nakatsubo, S.; Furukawa, Y.; Sazaki, G. Temperature Dependence of the Growth Kinetics of Elementary Spiral Steps on Ice Basal Faces Grown from Water Vapor. Cryst. Growth Des. 2018, 18, 786-793. [CrossRef]

20. Sazaki, G.; Zepeda, S.; Nakatsubo, S.; Yokomine, M.; Furukawa, Y. Quasi-liquid layers on ice crystal surfaces are made up of two different phases. Proc. Natl. Acad. Sci. USA 2012, 109, 1052-1055. [CrossRef]

21. Asakawa, H.; Sazaki, G.; Nagashima, K.; Nakatsubo, S.; Furukawa, Y. Two types of quasi-liquid layers on ice crystals are formed kinetically. Proc. Natl. Acad. Sci. 2016, 113, 1749-1753. [CrossRef] 
22. Murata, K.; Asakawa, H.; Nagashima, K.; Furukawa, Y.; Sazaki, G. Thermodynamic origin of surface melting on ice crystals. Proc. Natl. Acad. Sci. 2016, 113, E6741-E6748. [CrossRef]

23. Murata, K.; Asakawa, H.; Nagashima, K.; Furukawa, Y.; Sazaki, G. In situ Determination of Surface Tension-to-Shear Viscosity Ratio for Quasiliquid Layers on Ice Crystal Surfaces. Phys. Rev. Lett. 2015, 115, 256103. [CrossRef] [PubMed]

24. Nagata, Y.; Hama, T.; Backus, E.H.G.; Mezger, M.; Bonn, D.; Bonn, M.; Sazaki, G. The Surface of Ice under Equilibrium and Nonequilibrium Conditions. Acc. Chem. Res. 2019, 52, 1006-1015. [CrossRef] [PubMed]

25. Jaecker-Voirol, A.; Ponche, J.L.; Mirabel, P. Vapor pressures in the ternary system water-nitric acid-sulfuric acid at low temperatures. J. Geophys. Res. 1990, 95, 11857. [CrossRef]

26. Goldan, P.D.; Kuster, W.C.; Albritton, D.L.; Fehsenfeld, F.C.; Connell, P.S.; Norton, R.B.; Huebert, B.J. Calibration and tests of the filter-collection method for measuring clean-air, ambient levels of nitric acid. Atmos. Environ. 1983, 17, 1355-1364. [CrossRef]

27. Hanke, M.; Umann, B.; Uecker, J.; Arnold, F.; Bunz, H. Atmospheric measurements of gas-phase $\mathrm{HNO}_{3}$ and $\mathrm{SO}_{2}$ using chemical ionization mass spectrometry during the MINATROC field campaign 2000 on Monte Cimone. Atmos. Chem. Phys. 2003, 3, 417-436. [CrossRef]

28. Michelson, A.A.; Morley, E.W. On the relative motion of the Earth and the luminiferous ether. Am. J. Sci. 1887, s3-34, 333-345. [CrossRef]

29. Beyer, K.D.; Hansen, A.R. Phase diagram of the nitric acid/water system: Implications for polar stratospheric clouds. J. Phys. Chem. A 2002, 106, 10275-10284. [CrossRef]

30. Yokoyama, E.; Yoshizaki, I.; Shimaoka, T.; Sone, T.; Kiyota, T.; Furukawa, Y. Measurements of Growth Rates of an Ice Crystal from Supercooled Heavy Water under Microgravity Conditions: Basal Face Growth Rate and Tip Velocity of a Dendrite. J. Phys. Chem. B 2011, 115, 8739-8745. [CrossRef]

31. Thibert, E.; Dominé, F. Thermodynamics and Kinetics of the Solid Solution of $\mathrm{HNO}_{3}$ in Ice. J. Phys. Chem. $B$ 1998, 102, 4432-4439. [CrossRef]

32. Wagner, R.S.; Ellis, W.C. Vapor-liquid-solid mechanism of single crystal growth. Appl. Phys. Lett. 1964, 4, 89-90. [CrossRef]

33. Nagashima, K.; Sazaki, G.; Hama, T.; Asakawa, H.; Murata, K.; Furukawa, Y. Direct Visualization of Quasi-Liquid Layers on Ice Crystal Surfaces Induced by Hydrogen Chloride Gas. Cryst. Growth Des. 2016, 16, 2225-2230. [CrossRef]

34. Nagashima, K.; Sazaki, G.; Hama, T.; Murata, K.; Furukawa, Y. Uptake Mechanism of Atmospheric Hydrogen Chloride Gas in Ice Crystals via Hydrochloric Acid Droplets. Cryst. Growth Des. 2018, 18, 4117-4122. [CrossRef]

(C) 2020 by the authors. Licensee MDPI, Basel, Switzerland. This article is an open access article distributed under the terms and conditions of the Creative Commons Attribution (CC BY) license (http://creativecommons.org/licenses/by/4.0/). 